\title{
Regulation of Waste Management under Spatial Competition *
}

\author{
Juan Carlos Bárcena-Ruiz ${ }^{a \dagger}$ and F. Javier Casado-Izaga ${ }^{a \ddagger}$ \\ ${ }^{a}$ Universidad del País Vasco UPV/EHU, Spain
}

\begin{abstract}
We consider a regulator with different sensibilities with regard to consumers and producers. This regulator has a say in (i) the location of a waste collection point; (ii) who pays the waste transportation costs to the collection point; and (iii) whether firms locate simultaneously or sequentially. We find that these decisions depend on the regulator's profile and on the relationship between waste and product transportation costs. They also have an impact on competition between firms and on welfare. When the regulator requires firms to pay waste transportation costs the optimal location of the collection point is in the middle of the city, regardless of whether firms' locations are chosen simultaneously or sequentially. When the regulator decides that the cost is to be paid by consumers and that firms locate sequentially the collection point is located outside the middle of the city.
\end{abstract}

JEL classification: D43, L13, Q53.

Keywords: Spatial competition, firms' locations, waste management, collection point.

\footnotetext{
*The authors gratefully acknowledge financial support from Ministerio de Ciencia y Tecnología and FEDER (ECO2012-32299).

${ }^{\dagger}$ Corresponding author. Departamento de Fundamentos del Análisis Económico I. Facultad de Ciencias Económicas y Empresariales. Universidad del País Vasco, UPV/EHU. Av. Lehendakari Agirre 83, 48015, Bilbao, Spain. Phone: + 349460138 29. Fax: + 3494601 38 91. E-mail: juancarlos.barcena@ehu.es.

‡Departamento de Fundamentos del Análisis Económico I. Facultad de Ciencias Económicas y Empresariales. Universidad del País Vasco, UPV/EHU. Av. Lehendakari Agirre 83, 48015, Bilbao, Spain. Phone: + 349460138 32. Fax: + 349460138 91. E-mail: franciscojavier.casado@ehu.es.
} 


\section{Introduction}

The production and distribution of goods causes waste and rubbish that firms must get rid of. Disposing of waste is expensive as waste materials must be transported to a collection point. This is usually done in batches and not unit by unit as waste is continuously generated, because the latter system would be very costly. The location of the collection point is thus crucial in determining the cost to firms of transporting their waste.

In this paper we study a duopoly in a linear city. We consider that firms and consumers share the same cost structure: firms use it to get rid of their waste and consumers to transport goods home. These costs are quadratic with the distance traveled, as suggested by d'Aspremont et al (1979) to avoid the problem of there being no price equilibrium for some locations of the two firms. The difference between consumers and firms is that each consumer transports home one unit of the good, while all waste is transported at the same time to the collection point. We consider a collection point alone rather than a landfill, because a landfill generates negative externalities which would lead it to be located outside the residential area. Thus, we do not assume that the collection point has any negative externalities, so it can be located within the city limits when it is of interest to do so from a social welfare point of view. ${ }^{1}$

Literature on the location of firms begins with the seminal paper by Hotelling (1929), who states the principle of minimum differentiation in a linear city. In this paper consumers have linear transportation costs but this assumption causes problems in obtaining an equilibrium in prices when firms are close enough together. This problem is analyzed by d'Aspremont et al. (1979), who sug-

\footnotetext{
${ }^{1}$ Plants for processing and classifying waste are commonly located within residential areas when their negative effects can be considered negligible. One example of collection points located in the residential areas of the cities can be found in municipial garbage processing plants. For example in Vitoria-Gasteiz, a city located in northern Spain, one of the plants that process the garbage is located close to the city's medieval Old Town, a core city center district. Recently 79 small apartments for young people have been built adjacent to the garbage processing plant near the city center. Our paper does not refer to urban garbage but waste produced by firms, but the same arguments can be used to justify the central location of the collection point for a broad variety of non-dangerous waste materials.
} 
gest a different approach to get price equilibria in all subgames by considering quadratic transportation costs. Under this cost structure firms locate at the endpoints of the city (the so-called principle of maximum differentiation). Later Lambertini (1994) and Tabuchi and Thisse (1995) extend this model by allowing firms to locate outside city boundaries given that they have incentives to locate where there are no consumers. In this setting, in the simultaneous case firms locate symmetrically outside the city boundaries at a distance from their rivals equivalent to 1.5 times the size of the city. In the sequential case the leader locates in the middle of the market and the follower locates at a distance from the leader equivalent to the size of the city. There are several different extensions of these models but to our knowledge literature on the location of firms has never before addressed the economic consequences of the location of a collection point.

Another branch of literature analyzes related issues. Thisse and Wildasin (1992) consider a single public facility whose location is fixed and two firms that choose their locations. They also assume that the location of households and land rent are endogenously determined, but in their model the price of the good sold by the two firms is exogenously given. Morrissey and Browne (2004) review the types of model that are currently used in the area of municipal waste management. ReVelle and Eiselt (2005) review papers that analyze the location of facilities, focusing on models that consider discrete and continuous optimization.

To analyze social welfare effects we use a weighted welfare function which can be interpreted as a special case for private duopolies of the generalized social welfare function proposed by White (2002). That function gives different weights to consumer and producer surpluses and has been used before in location models (see e.g. Hamoudi and Risueño (2012), Bárcena-Ruiz and Casado-Izaga (2014), Bárcena-Ruiz et al. (2014)). The function allows to analyze the behavior of a regulator who may have different sensitivities with respect to firms' profits and 
the consumer surplus.

We focus on two alternative settings: first we consider that firms pay waste transportation costs; second we assume that consumers equally share those costs regardless of the location of the collection point. In the first case the price set by the firms comprises the cost of transporting the waste. In the second setting the public authorities impose a uniform tax that finances all the costs of collecting certain spent goods. For example within the EU countries such as France, Italy and Spain have ruled that collecting used tires is the responsibility of producers, but in other countries, e.g. Denmark and the Slovak Republic, the state takes this responsibility and finances the relevant operations through a tax (see European Tyre \& Rubber, 2011). From the point of view of our analysis what is relevant is not who is responsible but whether firms are allowed to finance operations through a tax or must pay the relevant expenses themselves. ${ }^{2}$

We find that when firms pay the waste transportation costs the optimal location of the collection point is in the middle of the city, regardless of whether firms decide their locations simultaneously or sequentially. The collection point acts as a centripetal force for the location of both firms because there is a cost reduction effect that pushes them both to locate near the collection point. Thus, firms locate closer together when there is a collection point than when disposing of waste is free. As a result competition between firms increases, which results in lower prices. Moreover, a regulator who has a say in the timing of the location game can influence the decisions of firms. The regulator can force a simultaneous choice of locations when it is very concerned about firms' profits and a sequential choice of locations when it is very concerned about the consumer surplus. For example, when the regulator must approve the location of firms by granting an operating certificate, both locations could be approved at the same time or on

\footnotetext{
${ }^{2}$ In those countries where the tax system is used the recovery and recycling of end of life tires is financed by a tax levied on tire production and subsequently passed on to consumers. When the responsibility lies with producers it is commonly financed through an environmental fee generally applied to the producer's price, regardless of the location of the collection point.
} 
different days. In the first case firms locate symmetrically around the collection point, but in the second case the leader locates at the location of the collection point and the follower locates far from it.

When consumers pay the waste transportation cost through a tax the optimal location for the collection point is outside the middle of the city only when firms decide their locations sequentially. As when firms pay the cost, if the regulator is concerned about firms' profits a simultaneous choice of locations is preferred. In this setting the location decisions of firms (be they simultaneous or sequential) do not depend on waste transportation costs.

Finally, we analyze the decisions made by the regulator regarding who pays waste transportation costs and whether firms locate simultaneously or sequentially, and find that they depend on how sensitive the regulator is towards consumers and producers, and on the relationship between waste and product transportation costs. A regulator who is very concerned about firms' profits chooses the tax system and thus consumers pay waste transportation costs. ${ }^{3}$ Otherwise, weighted welfare is greater when firms pay these costs, so the regulator decides accordingly. In the latter case, when the regulator is highly concerned about the consumer surplus a sequential choice of locations is better.

The rest of the paper is organized as follows. Section 2 presents the basic model. Section 3 considers that firms pay waste transportation costs. Section 4 studies the locations of firms when this cost is borne by consumers. Section 5 compares the results, and Section 6 draws conclusions.

\section{The basic model}

Consumers are distributed uniformly and with unitary density along a linear city, in the interval $[0,1]$. Consumers' locations are denoted by $x$. They transport their purchases home at a cost $t d^{2}$, where $t$ is a positive constant and $d$ is the distance traveled from the firm's location to the consumer's home. Each

\footnotetext{
${ }^{3}$ Depending on the relationship between the parameters sometimes simultaneous location is better and at other times a sequential choice of locations is preferable.
} 
consumer buys one unit of the good at the lowest delivered price, considered as the mill price plus transportation cost. Each consumer derives a surplus from consumption, gross of price and transportation costs, denoted by $s$. We assume that $s$ is large enough for each consumer to buy one unit of the product.

There are two private firms indexed by $i(i=1,2)$ competing in the market. Let $l_{i} \in R$ denote the location of firm $i$. Firms may therefore locate outside the linear city where consumers are distributed. For the sake of simplicity, we assume that firm 1 is located to the left of or at the same point as firm 2: $l_{1} \leq l_{2}$. Firms' production costs are normalized to zero with no loss of generality. The production of the good involves the production of waste. In the basic model we consider that this waste must be transported from each firm to a waste collection point located at $l_{w} \in R$. The waste transportation costs of firm $i$ $\left(W T C_{i}\right)$ are described by the following equation: $W T C_{i}=g\left(l_{i}-l_{w}\right)^{2} q_{i}$, where $g$ is a positive constant and $q_{i}$ is the production and demand of firm $i$. Thus, the waste is transported by the firm to a collection point and waste transportation costs are quadratic with the distance traveled and proportional to the amount of waste transported. ${ }^{4}$ The location of the firms and that of the collection point cannot be changed in the future. In the alternative model proposed below each consumer pays a uniform tax to the firms for transporting waste, so firms do not have to bear this cost. The tax collects exactly the cost of transporting waste and shares the total amount equally among all consumers. This alternative scenario is analyzed later.

The location of the waste collection point is decided by a regulator whose objective function is weighted welfare $(W)$ defined as the weighted sum of firms' profits $\left(\pi_{1}+\pi_{2}\right)$ and the consumer surplus $(C S)$ : $W=\alpha\left(\pi_{1}+\pi_{2}\right)+(1-$ $\alpha) C S, \alpha \in[0,1]$. Given that all consumers buy one unit of the good, when $\alpha=1 / 2$ maximizing $W$ is equivalent to minimizing the sum of consumers'

\footnotetext{
${ }^{4}$ With regard to the relationship between $t$ and $g$ it is not clear which one is higher, it depends on the amount of waste generated in producing one unit of the good and on the nature of the waste: very hazardous waste would be very costly to transport.
} 
transportation costs and waste transportation costs.

Let $p_{i}$ denote the price set by firm $i(i=1,2)$. First, we examine the location of the consumer who is indifferent between buying from one firm or the other. The location of this consumer, $\bar{l}$, can be obtained from the following indifference condition, which indicates that the total cost of buying from firm 1 (price plus transportation cost) is the same as that of buying from firm 2 :

$$
p_{1}+t\left(\bar{l}-l_{1}\right)^{2}=p_{2}+t\left(\bar{l}-l_{2}\right)^{2} \text {. }
$$

From (1) the following is obtained:

$$
\bar{l}=\frac{l_{1}+l_{2}}{2}+\frac{p_{2}-p_{1}}{2 t\left(l_{2}-l_{1}\right)} .
$$

Thus, the respective demands of firms 1 and 2 when they locate at different places $\left(l_{1} \neq l_{2}\right)$ are given by $q_{1}$ and $q_{2}$ :

$$
q_{1}=\left\{\begin{array}{cc}
\bar{l} & \text { if } 0 \leq \bar{l} \leq 1 \\
1 & \text { if } \bar{l}>1 \\
0 & \text { if } \bar{l}<0
\end{array} \quad, q_{2}=\left\{\begin{array}{cc}
1-\bar{l} & \text { if } 0 \leq 1-\bar{l} \leq 1 \\
1 & \text { if } 1-\bar{l}>1 \\
0 & \text { if } 1-\bar{l}<0
\end{array}\right.\right.
$$

Thus, consumer surplus in the basic model can be expressed as: $C S=$

$s-p_{1} q_{1}-p_{2} q_{2}-\int_{0}^{\bar{l}} t\left(x-l_{1}\right)^{2} d x-\int_{\bar{l}}^{1} t\left(x-l_{2}\right)^{2} d x$. Consumers' total transportation costs $(T T C)$ are $T T C=\int_{0}^{\bar{l}} t\left(x-l_{1}\right)^{2} d x+\int_{\bar{l}}^{1} t\left(x-l_{2}\right)^{2} d x$.

\section{Firms pay waste transportation costs}

We consider first that firms choose their locations simultaneously. We then assume that one firm acts as a leader in the choice of locations and the other as a follower. Then the regulator determines the optimal location of the collection point in each scenario, and finally we compare simultaneous and sequential results.

\subsection{Firms simultaneously decide their locations}

In this case the game played by the firms has two stages. In the first stage firms simultaneously decide their locations. In the second stage firms simultaneously set prices. To obtain a subgame perfect Nash equilibrium the game is solved by backward induction. 
In the second stage of the game firms simultaneously choose prices. The objective function of firm $i$ is its profit function:

$$
\pi_{i}\left(p_{i}, p_{j}\right)=p_{i} q_{i}-g\left(l_{i}-l_{w}\right)^{2} q_{i} ; i, j=1,2 ; i \neq j .
$$

From the first order condition for each firm we obtain equilibrium prices when both firms sell the good: ${ }^{5}$

$$
\begin{aligned}
& p_{1}=\frac{t\left(l_{2}-l_{1}\right)\left(2+l_{1}+l_{2}\right)+g\left(2 l_{1}^{2}+l_{2}^{2}-4 l_{1} l_{w}-2 l_{2} l_{w}+3 l_{w}^{2}\right)}{3}, \\
& p_{2}=\frac{t\left(l_{2}-l_{1}\right)\left(4-l_{1}-l_{2}\right)+g\left(l_{1}^{2}+2 l_{2}^{2}-2 l_{1} l_{w}-4 l_{2} l_{w}+3 l_{w}^{2}\right)}{3} .
\end{aligned}
$$

The demand of firms 1 and 2 when both sell in the market is determined by expressions (2) and (3):

$$
\begin{aligned}
& q_{1}=\frac{t\left(2+l_{1}+l_{2}\right)+g\left(l_{1}+l_{2}-2 l_{w}\right)}{6 t}, \\
& q_{2}=\frac{t\left(4-l_{1}-l_{2}\right)-g\left(l_{1}+l_{2}-2 l_{w}\right)}{6 t} .
\end{aligned}
$$

By substituting expressions (5) to (8) in the profit functions of the two firms we obtain:

$$
\begin{aligned}
& \pi_{1}=\frac{\left(l_{2}-l_{1}\right)\left[t\left(2+l_{1}+l_{2}\right)+g\left(l_{1}+l_{2}-2 l_{w}\right)\right]^{2}}{18 t} \\
& \pi_{2}=\frac{\left(l_{2}-l_{1}\right)\left[t\left(-4+l_{1}+l_{2}\right)+g\left(l_{1}+l_{2}-2 l_{w}\right)\right]^{2}}{18 t} .
\end{aligned}
$$

Now the first stage of the game can be solved and the equilibrium locations $\left(l_{1}\right.$ and $\left.l_{2}\right)$ can be determined as a function of the location of the collection point when both firms decide them simultaneously. From the first order conditions for firms 1 and $2\left(\frac{\partial \pi_{1}}{\partial l_{1}}=0\right.$ and $\left.\frac{\partial \pi_{2}}{\partial l_{2}}=0\right)$ the following is obtained:

$$
\begin{aligned}
& t\left(2+3 l_{1}-l_{2}\right)+g\left(3 l_{1}-l_{2}-2 l_{w}\right)=0, \\
& t\left(4+l_{1}-3 l_{2}\right)+g\left(l_{1}-3 l_{2}+2 l_{w}\right)=0 .
\end{aligned}
$$

\footnotetext{
${ }^{5}$ The second order conditions of the problems that we analyze are always met.
} 
Manipulating the first order conditions, the reaction functions in the locations of the firms are obtained:

$$
\begin{aligned}
& l_{1}\left(l_{2}\right)=\frac{l_{2}}{3}+\frac{-2 t+2 g l_{w}}{3(g+t)}, \\
& l_{2}\left(l_{1}\right)=\frac{l_{1}}{3}+\frac{4 t+2 g l_{w}}{3(g+t)} .
\end{aligned}
$$

By solving these equations the equilibrium locations can be found. When they are decided simultaneously, the locations of the two firms as a function of the location of the collection point are: $l_{1}=\frac{-t+4 g l_{w}}{4(g+t)}$ and $l_{2}=\frac{5 t+4 g l_{w}}{4(g+t)}$. It is easy to see that $\frac{\partial l_{i}}{\partial l_{w}}=\frac{g}{g+t}>0(i=1,2)$ and that $l_{2}-l_{1}=\frac{3 t}{2(g+t)}$. Thus as the collection point shifts to the right both firms move to the right but the distance between them remains constant.

Now the optimal location of the collection point can be determined.

Proposition 1. When firms pay waste transportation costs and their locations are decided simultaneously the optimal location of the collection point is in the middle of the city: $l_{w}=\frac{1}{2}$.

Proof. In order to obtain the solution we maximize weighted welfare. From equations (2) to (10) and equilibrium locations (13) and (14), we obtain: $W=$ $\alpha\left(\pi_{1}+\pi_{2}\right)+(1-\alpha) C S=(1-\alpha) s-\frac{16 \operatorname{tg}(1-\alpha)\left(1-3 l_{w}+3 l_{w}^{2}\right)+t^{2}(85-157 \alpha)}{48(g+t)}$. Then, from the first order condition we find that the optimal location of the collection point is $l_{w}=\frac{1}{2}$.

Given the optimal location of the collection point equilibrium locations, firms' demands, prices, firms' profits and weighted welfare can be calculated:

$$
\begin{aligned}
l_{1} & =-\frac{1}{4}+\frac{3 g}{4(g+t)}, l_{2}=\frac{5}{4}-\frac{3 g}{4(g+t)}, q_{1}=q_{2}=\frac{1}{2}, \\
p_{1} & =p_{2}=\frac{3 t^{2}(11 g+8 t)}{16(g+t)^{2}}, \pi_{1}=\pi_{2}=\frac{3 t^{2}}{4(g+t)}, \\
W & =(1-\alpha) s-\frac{4 t g(1-\alpha)+t^{2}(85-157 \alpha)}{48(g+t)} .
\end{aligned}
$$

These results can be interpreted as follows. First, the standard demand effect pushes both firms towards the middle of the market, in order to locate close to 
all consumers. Second, the standard strategic effect pushes each firm to locate further from its rival to mitigate price competition. Third, a new centripetal effect appears: ${ }^{6}$ a cost reducing effect that pushes both firms to locate closer to the collection point in order to reduce waste transportation costs. When $g=0$, that is when transporting waste is free, this third effect is not active and the standard effects push both firms to locate outside the city at $l_{1}=-\frac{1}{4}$ and $l_{2}=\frac{5}{4}$. This is the result obtained by Lambertini (1994) and Tabuchi and Thisse (1995) in their simultaneous location game. In our case, the higher $g$ is, the closer both firms are to the middle of the city $\left(\frac{\partial l_{1}}{\partial g}>0\right.$ and $\left.\frac{\partial l_{2}}{\partial g}<0\right)$. The cost reducing effect pushes both firms to locate closer to the waste collection point. As $g$ goes to $+\infty, l_{1}$ and $l_{2}$ tend to $1 / 2$, thus approaching the minimum differentiation result.

Given that equilibrium locations are symmetric both firms set the same prices and obtain the same profits. In the standard case where the regulator attaches the same weight to consumers and producers (i.e. $\alpha=1 / 2$ ) the surprising result emerges that weighted welfare increases with parameter $g .{ }^{7}$ The reason for this result is the following. Given that it is always one unit of the good that is sold, prices do not play any role from a social welfare point of view as they are simply a monetary transfer from consumers to producers. Thus, when $g$ is very low $(g<t)$ firms are very far from each other and they react to an increase in $g$ by locating closer. As a result, there is a reduction in consumers' transportation costs that outweighs the increase in total waste transportation costs. When $g$ is such that $g \in(t, 2 t)$ an increase in $g$ pushes the two firms towards the first and third quartiles, which reduces both waste and product transportation costs. Finally, when $g>2 t$, as $g$ increases the reduction in total waste transportation costs outweighs the increase in consumers' transportation costs since firms are too close.

\footnotetext{
${ }^{6}$ Centripetal because the collection point is located in the middle of the market.

${ }^{7}$ It can be shown that $\frac{\partial\left(W T C_{1}+W T C_{2}\right)}{\partial g}>0$ if and only if $g<t$, and $\frac{\partial T T C}{\partial g}>0$ if and only if $g>2 t$.
} 
In general, it can be shown that $\frac{\partial W}{\partial g}>0$ if and only if $\alpha<9 / 17$. As $g$ increases both firms locate closer to the collection point, their prices and profits decrease but the consumer surplus increases. When $\alpha$ is low weighted welfare increases with $g$ because the consumer surplus is very important from a weighted welfare point of view. When $\alpha$ is high the opposite result holds, as firms' profits are now very important for weighted welfare and the fall in firms' profits reduces weighted welfare.

\subsection{Firms decide locations sequentially}

In this framework the game played by the firms has three stages. In the first stage the leader, firm 1, decides its location. In the second stage the follower, firm 2, observes the leader's location and makes its decision. Finally, in the third stage, both firms simultaneously set prices. To obtain a subgame perfect Nash equilibrium the game is solved by backward induction.

The last stage of the game has already been solved and equilibrium prices are given by equations (5) and (6). In the second stage of the game the follower (firm 2) chooses its location. Its profit function is given by equation (10) and then the location chosen by firm 2 is given by equation (14).

In the first stage of the game firm 1 chooses its location taking into account (9) and (14). Simple algebra shows that firm 1's profit function is: $\pi_{1}=\frac{4\left(2(g+t) l_{1}+5 t-2 g l_{w}\right)^{2}\left(2 t+g l_{w}-(g+t) l_{1}\right)}{243 t(g+t)}$. From the first order condition the following is obtained: $l_{1}=\frac{t+2 g l_{w}}{2(g+t)}$. As a result $l_{2}=\frac{3 t+2 g l_{w}}{2(g+t)}$. Thus, the distance between the two firms is $l_{2}-l_{1}=\frac{t}{g+t}$, and this distance is shorter than in the simultaneous case.

The leader firm should be aware that the follower could locate to its left. In that case, to preserve the equations assume now that firm 2 is the leader. Simple algebra shows that the follower (firm 1) would locate at $l_{1}\left(l_{2}\right)=\frac{l_{2}}{3}+\frac{-2 t+2 g l_{w}}{3(g+t)}$. As a result firm 2's profit function is $\pi_{2}=\frac{4\left(2(g+t) l_{2}-7 t-2 g l_{w}\right)^{2}\left(t-g l_{w}+(g+t) l_{2}\right)}{243 t(g+t)}$. The first order condition gives the following: $l_{2}=\frac{t+2 g l_{w}}{2(g+t)}$. This results in $l_{1}=$ 
$\frac{-t+2 g l_{w}}{2(g+t)}$, and the distance between the two firms is the same as before: $l_{2}-l_{1}=$ $\frac{t}{g+t}$.

The optimal location of the follower may lie to the right or to the left of the leader firm, but the leader always locates at $\frac{t+2 g l_{w}}{2(g+t)}$. The follower is indifferent between the optimal location to the right and leapfrogging to the optimal location to the left of the leader. In both cases the distance between the two firms is the same, the leader gets the same profits independently of the location of the follower (to the right or to the left) and the follower obtains the same profits from both optimal locations. With no loss of generality we assume that firm 1 is the leader and that it is located to the left of the follower, so $l_{1}=\frac{t+2 g l_{w}}{2(g+t)}$ and $l_{2}=\frac{3 t+2 g l_{w}}{2(g+t)}$. As in the simultaneous case: $\frac{\partial l_{i}}{\partial l_{w}}=\frac{g}{g+t}>0(i=1,2)$. As the collection point shifts to the right both firms move to the right but the distance between them is always the same: $\frac{t}{g+t}$.

Finally, the optimal location of the collection point can determined. To find the solution, we introduce the firms' locations for the sequential case in the weighted welfare function. It is straightforward to obtain the following: $W=$ $(1-\alpha) s-\frac{12 \operatorname{tg}(1-\alpha)\left(1-3 l_{w}+3 l_{w}^{2}\right)+t^{2}(47-87 \alpha)}{36(g+t)}$. The same solution is obtained when the leader firm is located to the right. From the first order condition maximizing weighted welfare the following result is obtained.

Proposition 2. When firms pay waste transportation costs and their locations are decided sequentially the optimal location of the collection point is in the middle of the city: $l_{w}=\frac{1}{2}$.

Now, equilibrium locations, firms' demands, prices, firms' profits and weighted welfare can be calculated (superscript $L$ stands for leader and $F$ stands for fol- 
lower):

$$
\begin{aligned}
l_{1}^{L} & =\frac{1}{2}, l_{2}^{F}=\frac{3}{2}-\frac{g}{g+t}, q_{1}^{L}=\frac{2}{3}, q_{2}^{F}=\frac{1}{3}, \\
p_{1}^{L} & =\frac{4 t^{2}}{3(g+t)}, p_{2}^{F}=\frac{t^{2}(5 g+2 t)}{3(g+t)^{2}}, \pi_{1}^{L}=\frac{8 t^{2}}{9(g+t)}, \pi_{2}^{F}=\frac{2 t^{2}}{9(g+t)}, \\
W^{L F} & =(1-\alpha) s-\frac{3 t g(1-\alpha)+t^{2}(47-87 \alpha)}{36(g+t)} .
\end{aligned}
$$

When $g=0$ the leader locates in the middle of the city and the follower locates at $l_{2}^{F}=\frac{3}{2}$ (the result first obtained by Lambertini (1994)). As $g$ increases the follower comes closer to the leader, who has a first mover advantage, and it is located at the same place as the collection point. Thus, the leader does not pay waste transportation costs. The follower locates at a distance $\frac{g}{g+t}$ from the leader. This distance decreases as $g$ increases because then the cost reduction effect that pushes the follower towards the collection point is stronger. The leader obtains higher profits, as usual in these models.

\subsection{Comparison of results}

A comparison of the profits obtained by the firms in the simultaneous and sequential cases reveals that the leader (follower) in location obtains higher (lower) profits than in the simultaneous case. This is because the leader and the collection point are located at the same place and the follower has to choose a worse location, far from both the collection point and consumers.

The comparison of firms' profits and the consumer surplus in the simultaneous and sequential cases is straightforward: on the one hand, firms' total profits are higher in the simultaneous case than under sequential choice of locations since the distance between the firms is greater; on the other hand, the consumer surplus is higher in the sequential case than under simultaneous choice of locations. It is easy to see that the difference between weighted welfare in the simultaneous case $(W)$ and in the sequential case $\left(W^{L F}\right)$ is: $W-W^{L F}=\frac{t(-67+123 \alpha)}{144(t+g)}$. There is therefore a critical value for $\alpha$, denoted by $\alpha_{1}=67 / 123$, such that weighted welfare is the same in both scenarios. When firms' profits are very 
important from a weighted welfare point of view $\left(\alpha>\alpha_{1}\right)$ weighted welfare is higher under simultaneous choice of location, but when the consumer surplus is very important for weighted welfare $\left(\alpha<\alpha_{1}\right)$ sequential choice of locations is better.

A regulator who has a say in when firms may locate could manipulate the timing of the location game. For example, when the regulator must approve the location of firms by granting an operating certificate both locations could be approved at the same time or on different days. The regulator can force a simultaneous choice when it is very concerned about firms' profits or a sequential choice of locations when it is very concerned about the consumer surplus.

\section{Consumers pay waste transportation costs}

In this alternative setting consumers bear the transportation costs for all the waste produced. ${ }^{8}$ They share the total amount equally through a uniform tax. As in the above section we study firms' equilibrium locations for a given location of the collection point when firms choose their locations either simultaneously or sequentially. Then the regulator determines the optimal location of the collection point, and finally the results are compared.

\subsection{Firms decide their locations simultaneously}

Consumers pay a uniform tax regardless whether they buy from firm 1 or from firm 2, so the determination of the location of the consumer who is indifferent between the two sellers is given by equation (1). The resolution of the game in this setting is straightforward as firms do not bear waste transportation costs, so equations (1) to (16) with $g=0$ give the results. Weighted welfare ( $W_{C}$, where subscript $C$ stands for consumers paying waste costs), can now be expressed as:

$$
W_{C}=(1-\alpha) s-\frac{3 g(1-\alpha)\left(13-16 l_{w}+16 l_{w}^{2}\right)+t(85-157 \alpha)}{48} .
$$

\footnotetext{
${ }^{8}$ In this case the consumer surplus must be reduced by this amount.
} 
From the first order condition maximizing weighted welfare the optimal location of the collection point can be determined straightforwardly.

Proposition 3. When consumers pay waste transportation costs and firms' locations are decided simultaneously the optimal location of the collection point is in the middle of the city: $l_{w}=\frac{1}{2}$.

The following results are thus obtained:

$$
\begin{aligned}
l_{1} & =-\frac{1}{4}, l_{2}=\frac{5}{4}, q_{1}=q_{2}=\frac{1}{2}, p_{1}=p_{2}=\frac{3 t}{2}, \pi_{1}=\pi_{2}=\frac{3 t}{4}, \\
W_{C} & =(1-\alpha) s-\frac{27 g(1-\alpha)+t(85-157 \alpha)}{48} .
\end{aligned}
$$

Firms' locations do not depend on where the collection point is located because now there is no cost reduction effect. Thus, the collection point is located in the middle of the city to minimize waste transportation costs. The locations chosen by the firms are the same as those obtained by Lambertini (1994) and Tabuchi and Thisse (1995).

\subsection{Firms decide their locations sequentially}

We proceed as in section 3.2 taking into account that now $g=0$. In the last stage of the game equilibrium prices are given by equations (5) and (6) for $g=0$. In the second stage of the game the follower (firm 2) chooses its location. The profit function of firm 2 is given by equation (10) and then the location chosen by firm 2 is given by equation (14), in both cases for $g=0$.

In the first stage of the game firm 1 chooses its location taking into account (9) and (14) for $g=0$. Simple algebra shows that firm 1's profit function is $\pi_{1}=\frac{4 t\left(2 l_{1}+5\right)^{2}\left(2-l_{1}\right)}{243}$. From the first order condition the following is obtained: $l_{1}=\frac{1}{2}$. As a result $l_{2}=\frac{3}{2}$. Thus, the distance between the two firms is $l_{2}-l_{1}=1$ and this distance is shorter than in the simultaneous case. ${ }^{9}$

\footnotetext{
${ }^{9}$ Obviously the follower could adopt a location to the left of the leader but in that case firms' profits are the same. The sequential location equilibrium without waste transportation costs is analyzed by Lambertini (1994).
} 
Weighted welfare, $W_{C}^{L F}$ (where superscripts $L F$ stand for the sequential game and subscript $C$ stands for consumers paying waste transportation costs) can now be expressed as:

$$
W_{C}^{L F}=(1-\alpha) s-\frac{3 g(1-\alpha)\left(11-20 l_{w}+12 l_{w}^{2}\right)+t(47-87 \alpha)}{36} .
$$

From the first order condition the optimal location of the collection point can be calculated straightforwardly.

Proposition 4. When consumers pay waste transportation costs and firms' locations are decided sequentially the optimal location of the collection point is $l_{w}=\frac{5}{6}$.

The following results are thus obtained:

$$
\begin{aligned}
l_{1}^{L} & =\frac{1}{2}, l_{2}^{F}=\frac{3}{2}, q_{1}^{L}=\frac{2}{3}, q_{2}^{F}=\frac{1}{3}, p_{1}^{L}=\frac{4 t}{3}, p_{2}^{F}=\frac{2 t}{3}, \pi_{1}^{L}=\frac{8 t}{9}, \\
\pi_{2}^{F} & =\frac{2 t}{9}, W_{C}^{L F}=(1-\alpha) s-\frac{8 g(1-\alpha)+t(47-87 \alpha)}{36} .
\end{aligned}
$$

As firms' locations, prices and market share do not depend on the location of the collection point the regulator locates it so as to minimize waste transportation costs. Thus, the collection point is located between the two firms but closer to firm 1 as this firm's market share is twice that of firm 2 .

\subsection{Comparison of results}

By comparing weighted welfare under simultaneous and sequential locations we obtain the following: $W_{C}-W_{C}^{L F}=\frac{49 g(\alpha-1)+t(123 \alpha-67)}{144}$. There is thus a critical value for $\alpha$, denoted by $\alpha_{2}=(49 g+67 t) /(49 g+123 t)$, such that weighted welfare is the same in both scenarios. When firms' profits are very important from a weighted welfare point of view $\left(\alpha>\alpha_{2}\right)$ weighted welfare is higher under simultaneous choice of locations, but when the consumer surplus is very important for weighted welfare $\left(\alpha<\alpha_{2}\right)$ a sequential choice of locations is better. As before, a regulator who has a say in when firms may locate can 
force a simultaneous choice when he/she is very concerned about firms' profits $\left(\alpha>\alpha_{2}\right)$ and a sequential choice of locations otherwise.

Next we compare the simultaneous and sequential results from a weighted welfare point of view when firms pay waste transportation costs and when these costs are paid by consumers.

\section{Weighted welfare analysis}

With no loss of generality, define $\lambda=g / t$. Thus $\alpha_{2}$ can be rewritten as $\alpha_{2}=(49 \lambda+67) /(49 \lambda+123)$. As a result of the comparisons in sections 3.3 and 4.3 , three different zones can be distinguished from a weighted welfare point of view (see Figure 1). Zone I is such that $\alpha<\alpha_{1}$; in this zone weighted welfare is greater under a sequential choice of locations regardless of who pays the waste transportation costs. In zone II, i.e. when $\alpha \in\left[\alpha_{1}, \alpha_{2}\right],{ }^{10}$ a comparison must be made between weighted welfare under simultaneous locations when firms pay waste transportation costs, and under sequential locations when consumers pay waste transportation costs. Finally in zone III, i.e. when $\alpha>\alpha_{2}$, weighted welfare under simultaneous location is compared when firms pay waste transportation costs and when consumers pay waste transportation costs.

\footnotetext{
${ }^{10}$ At the lower limit of the interval $W=W^{L F}$, in which case there is no difference between simultaneous and sequential choices when firms pay waste transportation costs. At the upper limit $W_{C}=W_{C}^{L F}$, so there is no difference between simultaneous and sequential choices when consumers pay waste transportation costs.
} 


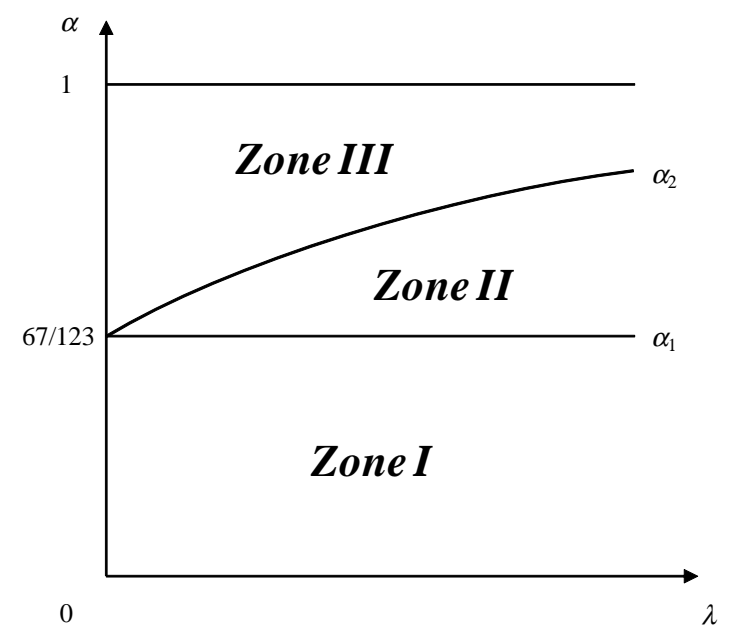

Figure 1. Zones arising when comparing weighted welfare.

In zone I $W^{L F}-W_{C}^{L F}=t \lambda(13+2 \lambda-\alpha(23+2 \lambda)) / 9(1+\lambda)$. As $\alpha<$ $\alpha_{1}$, it results that that $W^{L F}>W_{C}^{L F}$. That is, when the regulator is very concerned about consumers a sequential choice of locations is better if firms pay waste transportation costs. This is because firms are closer than when consumers pay the costs, and both the prices and the transportation costs of the product are lower. Therefore, when $\alpha<\alpha_{1}$ the regulator makes firms pay waste transportation costs, and draws up operating certificates for firms to ensure that they locate sequentially.

In zone II $W-W_{C}^{L F}=t(-67+16 \lambda(13+2 \lambda+\alpha(123-16 \lambda(23+2 \lambda))) / 144(1+\lambda)$. Thus in this zone, as shown in Figure 2, when $\alpha$ is high enough $\left(\alpha>\alpha_{3}=\right.$ $\left.\left(67-208 \lambda-32 \lambda^{2}\right) /\left(123-368 \lambda-32 \lambda^{2}\right)\right)$ a sequential choice of locations is better when consumers pay waste transportation costs (firms' profits are higher in this setting because they pay no waste transportation costs). A simultaneous choice is better when firms pay those costs.

In zone III $W-W_{C}=3 t \lambda(3(4+\lambda)-\alpha(20+3 \lambda)) / 16(1+\lambda)$. Thus as shown in Figure 2, for high values of $\alpha\left(\alpha>\alpha_{4}=3(4+\lambda) /(20+3 \lambda)\right)$, weighted welfare 
is greater when consumers pay waste transportation costs. The higher $\alpha$ is the more attractive the profits are for weighted welfare and thus a situation in which firms are very far from each other and do not pay waste transportation costs is preferred.

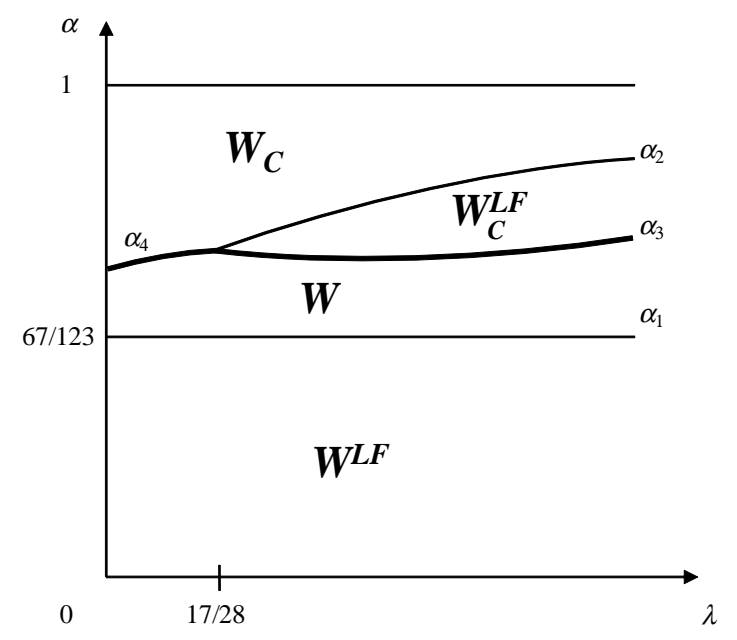

Figure 2. Best options from a weighted welfare point of view.

A overall look at Figure 2 shows that as $\alpha$ increases firms' profits have a greater effect on weighted welfare, so for a high enough value of $\alpha(\alpha>$ $\left.\min \left\{\alpha_{3}, \alpha_{4}\right\}\right)$ it is better that consumers pay waste transportation costs. Thus, the regulator levies taxes to finance these costs. For these values of $\alpha$, when $\lambda$ is low enough $(\lambda<17 / 28)$ weighted welfare is always greater under simultaneous locations. Otherwise the result depends on the profile of the regulator: when $\alpha>$ $\alpha_{2}\left(\alpha<\alpha_{2}\right)$ the regulator prefers simultaneous (sequential) location decisions.

When the regulator is very concerned about the consumer surplus, weighted welfare is greater when firms pay waste transportation costs for a low enough value of $\alpha\left(\alpha<\min \left\{\alpha_{3}, \alpha_{4}\right\}\right)$. In this zone, when $\alpha$ is high enough $(\alpha>67 / 123)$ the regulator prefers simultaneous location decisions. Finally, when concerns 
about the consumer surplus are very high $(\alpha<67 / 123)$ the best option is a sequential game as it improves the consumer surplus.

\section{Conclusions}

In this paper we analyze the optimal location of a collection point in a linear city. Its optimal location is in the middle of the city when firms pay waste transportation costs and decide their locations simultaneously or sequentially. The collection point acts as a centripetal force that attracts both firms because there is a cost reduction effect that forces both firms to locate close to the collection point. Thus, firms locate closer together when there is a collection point than when disposing of waste is free. As a result competition between firms increases, resulting in lower prices.

When consumers finance waste transportation costs through a tax and firms locate sequentially the collection point is located outside the middle of the city, because the locations of the firms do not depend on that of the collection point. In this case the regulator sets the collection point between the locations adopted by the two firms in order to minimize waste transportation costs.

A regulator who has a say in when firms may locate can control the timing of the location game and determine whether waste transportation costs are paid by the firms or financed by a uniform tax on all consumers. A regulator concerned about firms' profits can force a simultaneous choice of locations and levy a tax on consumers to cover waste transportation costs. The regulator forces a sequential choice of locations when firms pay waste transportation costs and he/she is very concerned about the consumers surplus. When the regulator is not strongly concerned there may be other choices such as simultaneous choice

of locations when firms pay waste transportation costs, and sequential choice of locations when consumers pay a tax to finance those costs.

\section{References}

Bárcena-Ruiz, J.C., F.J. Casado-Izaga. 2014. Zoning under Spatial Price 
Discrimination, Economic Enquiry, 52, 659-665.

Bárcena-Ruiz, J.C., F.J. Casado-Izaga, H. Hamoudi. 2014. Optimal Zoning of a Mixed Duopoly, Annals of Regional Science, 52, 141-153.

d'Aspremont C., J.J. Gabszewicz, J-F Thisse. 1979. On Hotelling's stability in competition, Econometrica, 47, 1145-1150.

European Tyre \& Rubber Manufacters' Association. 2011. End of life tyres. A valuable resource with growing potential. On line access at: http://www.etrma.org

Hamoudi H., M. Risueño 2012. The effects of zoning in spatial competition, Journal of Regional Science, 52, 361-374.

Harsanyi J.C. 1995. Cardinal welfare, individualistic ethics, and interpersonal comparisons of utility. Journal of Political Economy, 63, 309-321.

Hotelling H. 1929. Stability in competition. Economic Journal, 39, 41-57.

Lambertini L. 1994. Equilibrium locations in the unconstrained Hotelling game. Economic Notes, 23, 438-446.

Morrissey A.J., J. Browne 2004. Waste management models and their application to sustainable waste management. Waste Management, 24, 297-308.

ReVelle, C. S., H.A. Eiselt. 2005. Location analysis: A synthesis and survey. Europen Journal of Operational Research, 165, 1-19.

Tabuchi T., J-F. Thisse. 1995. Asymmetric equilibria in spatial competition. International Journal of Industrial Organization, 13, 213-227.

Thisse J-F., D.E. Wildasin. 1992. Public facility location and urban spatial structure. Equilibrium and welfare analysis. Journal of Public Economics, 48, 83-118.

White M.D. 2002. Political manipulation of a public firm's objective function. Journal of Economic Behavior and Organization, 49, 487-499. 